\title{
Connecting professionalism, learning and identity
}

\author{
Manon C. P. Ruijters ${ }^{\mathrm{a}} \&$ P. Robert-Jan Simons ${ }^{\mathrm{b1}}$ \\ ${ }^{a}$ Free University of Amsterdam \\ ${ }^{b}$ Visie op leren, Amsterdam
}

\begin{abstract}
Annotation
This is a conceptual article in which we try to connect some of our previous publications into a coherent new model of learner identity. The first phase of our research concerns the research and theories about professional and work-related learning, followed by work on the learning landscape: a metaphor for organizational learning. The third phase looks at added learning preferences: five ways of work-related learning. Phase four introduces the concept of the learning professional, and phase five looks at research and theories about professional identity: what inalienably connects: who you are (person), the work you do (profession) and the context in which you shape it. In the discussion, we try to explain how the various models can be connected, differentiated and integrated. Professional identity is the basis for all the other approaches. In an integrated set of questions, we bring it all together, introducing the new concept of learner identity and focusing on consequences for facilitating a professional learning culture.
\end{abstract}

Keywords: professional learning, professional identity, learning communities, categories of learning, professional learning culture, learning preferences

\section{Introduction}

Professions are an extended field of research. But do we, as researchers, also create a theory for professions? We agree with Nolin (2008) that "professions need researchers to develop definitions, standards and theories concerning the key concepts of profession, professionalization and professionalism in order to increase the quality of the professional practice of professionals." In this context, Nolin gives an overview of stories of development in the field, not so much in phases, but in perspectives, regarding the ways researchers deal with the key concepts of profession and professionalization. He distinguishes three stages of thinking about professions. In stage 1 (1937-1970) professions were seen as instruments of enlightenment and had a key function in the modernization of society. They have prestige, and research is focusing on their well described attributes. Stage 2 (1960-1980) professions were more about dominance than service. More professions sought recognition and efforts were made to create a 
hierarchy of professions, semi-professions and non-professions. Attention has shifted from the difficult concept of profession to the process of professionalization. In stage 3 (1980- ?), the period of power approach, professions are seen as self-serving interest groups involved in powerplay and competition with each other. Following some others (i.e. Freidson, 2001), Nolin (2008) proposed to work towards a fourth stage of thinking about professions, professionalization and professionalism. "Instead of the critical and distanced approach of stage three research, a fruitful starting point would be to collaborate with professionals, to produce theoretical instruments that help them in their practice." (p. 45). This is exactly what we have been doing in our research and practice. The five changes that Nolin proposed for stage four have been the key of our work: a) more attention to educating professionals (and we would like to add: the learning of professionals), b) instead of understanding the power problem, looking for ways to act on it, c) seeking collaborations within and between professions, d) making cultural and occupational diversity an asset instead of a problem, and e) executing qualitative studies.

In our analysis (Simons \& Ruijters, 2014) of the history of thinking about professionalism (referring to the core characteristics of a professional), we found seven shifts in thinking over time. Professionals used to have negative connotations, but at other times they were positively valued. Sometimes, professions were exclusive to some jobs (medical workers, lawyers, etc.), at times inclusive, taking in also nurses, teachers, artists, politicians. Sometimes, professions were working just for the money in contrast to doing something for fun (amateurs) or for free (gentlemen professionals). In some periods, professionalism was connected to high quality, at other times it was a kind of negative judgment, denoting low quality. The title of professional was not always regarded as positive. Hopkins University, for instance, provided advance instruction in contrast with (less valued) professional instruction. Sometimes professionals are highly educated workers with an education in Academia, sometimes they are knowledge workers with diverse educational backgrounds. In some periods professionals exerted power, and at other times they were servants. Finally, we found differences of emphasis over times in the autonomy of the professional and the restrictions an organizational context puts on them.

The positions taking in these seven dimensions differ not only over time but also over cultures and nations. It is important to realize that our research and practice took place in the Netherlands, although we also integrated in our work and research perspectives from other countries and the international literature. In the Netherlands, professionalism now has a predominantly positive connotation, more and more former so called semi-professionals are now seen as real professionals, professionalism is almost synonymic with high 
quality, it is a title of honor one wants to have, (applied) university education is seen as a condition for professionals (but the importance is declining), the power dimension is still at play but getting less important, interprofessional collaboration and collective professionalism are gaining in importance, some professionals within organizations complain about the lack of influence because of strict control (through protocols), but there are many debates about increasing the autonomy of professionals giving them professional space.

In this article, we aim to summarize our work on professionals and to develop an integrated model of professional learning (individual and collective) in which we conceptualize and relate learning, professionalism, learning preferences, organizational learning, professional identity and professional learning culture.

At the beginning of this century, we developed a first model of professional learning. (Simons \& Ruijters, 2001; 2004). This model developed over time in five phases and into three directions: professionalism, learning and identity:

1) the professional learning model arose;

2) the professional learning model became a more general model of learning landscapes in organizations (Simons \& Ruijters, 2001; Ruijters, 2006; Ruijters \& Simons, 2006);

3) we added a model of learning preferences (Ruijters, 2006; Simons \& Ruijters, 2008);

4) we developed our ideas of professional learning towards one of a learning professional (Simons \& Ruijters, 2014; Ruijters \& Simons, 2015);

5) we brought our thoughts about the learning professional into thinking about professional identity (Ruijters, 2015a; Van Oeffelt, Ruijters, Van Hees, \& Simons, 2017).

In this paper we try to integrate these models into one model of work-related and professional learning, introducing the new concepts of learner identity and professional learning culture. The five phases of our thinking and the related publications attracted a lot of attention in the Netherlands and other countries (Belgium, Estonia, Germany, Sweden). We were constantly asked about the relations between our models. In this article we will try to answer these questions:

a) What are the differences between our original models of professional and work-related models and the later ones?

b) How do learning preferences fit into our learning landscape?

c) How are professional identity and professional learning related?

d) What can be an integrative, combined model?

e) What does this mean for a professional learning culture? 
We introduce one conceptual scheme of questions that together help learners to study their learner identity (who am I as a professional learner?), connecting our previous work in one whole. All of this fits Nolin's (2008) fourth stage described above.

\section{Method}

In this article we brought together ideas and models that were written in diverse books and journals, both in English and in Dutch. From each of the articles we selected the key concepts and models. Although the five models of learning originate from the authors of this article, they have not yet been integrated in a unifying approach to learning. Moreover, we did not yet explicitly reflect about the differences between the models and the overlap.

The original articles that were the basis for the present article used various kinds of methodologies. Some of the methods came from our $\mathrm{PhD}$ students who published empirical qualitative studies that we used in integrative articles. Some articles used extensive literature review as a basis, others used existing theoretical models which were extended or changed, and, occasionally interview studies with professionals were used. The present article is a conceptual one.

The specific methods used for the different paragraphs were as follows. The first two models (professional learning and work-related learning) were conceptual ones. They gradually grew out of reformulation and integration of approaches we found in the literature, working with these approaches in our professional practice, in research by our $\mathrm{PhD}$ students (e.g. Berings, 2006; Doornbos, 2006) and with students from the university's Master's programs. They were taken as a starting point for the research in the next phases.

The learning landscape model was developed by Ruijters (2006) in her $\mathrm{PhD}$ research. The first version of the landscape model was a metaphorical extension of the model of work-related learning mentioned above. The various ways of learning were conceptualized as islands, bridges and polders, functioning at an organizational level. Ruijters (2006) used this to study organizational learning: how do organizations treat learning. In forms of action research in care and cure, consultancy firms, governmental organizations, police and fire brigade, and recently in social transitions on sustainability, the landscape model was applied as a diagnostic tool and developed further by working with it. Three main actions proved to be valuable: plotting the organization's collective learning patterns, designing possible interventions in an organization for learning and evaluating the impact of interventions at organizations afterwards. 
The learning preferences as described were studied through a 65 -item questionnaire. There were fifteen basic questions in the questionnaire, such as: a) situations in which one learns; b) learning with others; c) dealing with mistakes. For each basic question there were four or five specifications according to the five preferences. An example: "What annoys you in a learning situation?" The five possible answers were: $a$. When it is boring; $b$. When team members withdraw themselves from the team; c. When other people lack knowledge; $\mathrm{d}$. When I feel incompetent; e. When everything is fixed. For each of the $65 \mathrm{sub}$ questions respondents had to make a rating on a 5-point scale going from not attractive at all to very attractive. In an initial study, the newly devised questionnaire was tested with 713 elementary teachers, 92 school heads of elementary schools and 33 support people. The five learning preferences could be distinguished meaningfully and proved to be reliable, although improvements were necessary. The correlations between the scales were as expected. Meaningful relations were found with the variables of the educational system, age, experience and educational level. In a second study, a revised questionnaire was tested with 556 professionals from 12 different organizations.

The model of the learning professional was based on a systematic review of the literature about professionalism and its historical development. An approach developed by Gardner and Shulman was taken as a starting point. The 15 selected scientific articles found in the literature were used to check support for the Gardner and Shulman approach, to find contra-evidence and to extend their categories with new ones.

In 2012 Ruijters (2015b) started a large research project on professional identity. She and her colleagues interviewed a group of 47 professionals about their sense of professional identity, asking questions such as: What is a professional for you? How did your professionalism develop over time? How is your professionalism related to your personal and social development? How is your professionalism related to your organization and to professions? The interview-data were transcribed and analyzed through axial coding. The method underlying the final paragraph is conceptually integrating the various models. We searched for overlap, differences, extensions and especially relations between the different approaches and answered the questions described above.

\section{Phase 1: Professional learning and work-related learning}

In our earlier work we started by defining professions as fields of work that have an explicit body of knowledge described in handbooks and official (scientific) journals, and have standards of quality and professional associations (Greenwood, 1957; Thijssen, 1987). Professionals are a special type of worker 
who execute professions. Professional associations bring these professionals together, define the standards of quality, help to develop the body of knowledge and certify education and training that guarantee the quality of the learning outcomes. A professional is defined as someone working in such a professional field having an aligned combination of an explicit vision, a unique methodology and a set of high-quality tools and techniques. From our practice and inspired by several other theorists, we agreed with our colleagues and students that there are three main activities to be performed by a professional: working in practice, being connected with or carrying out research, and teaching others. (1) One can only be and remain a professional when working in practice with clients. For a doctor this means "working with patients", for a manager this means "working with employees". (2) A professional needs to be connected to the research in the disciplines connected to his work. (3) And the professional has an important role in transmitting professional experience to others and contributing to the professional field of expertise.

That being said, in our search for work-based learning of professionals and semi-professionals, we added learning experiences to these ideas of working. So, first, it is not only "working" in practice, but also learning in and from practice: being able to learn experientially. Second, it is not only being connected with research or being involved in research, but also learning from research. Therefore, we have redefined the second step in learning explicitly, and specified three ways to do so: critical, inquiry and theoretical learning (Bolhuis, 1996). Finally, the learning of "teaching others" is more than just that, it is helping the profession to develop and by doing so, learning yourself. This can be done through teaching, but also through writing books and articles, coaching, tutoring, lecturing at conferences, developing tools for others, being involved in discussions with other professionals, etc. This contribution to the outside professional world can, in our view, also be at the team or organizational level.

Professionals thus learn in three overlapping ways:

1) Elaboration: broadening their work-competences by learning from, and in practice;

2) Expansion: working on their theoretical knowledge and insights by learning explicitly from, and in research;

3) Externalization: bringing their practical and theoretical insights to the development of the profession and/or to team and organizations.

In 2004, we wrote an article (Simons \& Ruijters, 2004) that took us to the next stage in this thinking, from the learning of professionals to learning professionals. In doing so, we redefined what we see as a professional in this era. No longer the person with a good education and an approval from the association 
is a professional, but the one who is willing to keep learning central in his or her practice, the one who realizes that mastering a subject is not just the result of a good education. At the same time, this notion also meant that we no longer reserved the term professional for the occupations with a solid professional association. Being a professional in our perspective was then implying a mindset, even for those who would traditionally not be seen as professionals (such as the manager, the nurse, the secretary or the teacher).

\section{Phase 2: learning landscapes}

Working with the model of work-based learning in the practice of organizational development and learning made us realize that in practice the three forms of work-based learning (elaboration, expansion and externalization) did not behave as overlapping fields, but rather as islands. That was the beginning of thinking in terms of a metaphor; if these were islands within organizations, then what made the connections between the islands?

In Ruijters and Simons (2006) we analyzed and described these three basic ways of learning in a learning landscape metaphor "Islands of learning" containing three basic ways of learning: learning through practicing, inquiring and creating. The other parts of the landscape of learning were bridges and polders (see Figure 1). Bridges make connections between the outcomes of islands. Polders connect islands through new land. Making land out of the sea is called a "polder". This is a very important Dutch concept denoting the creation of new land in the sea.

\section{Islands}

Practicing is all the learning that is taking place (most of the time) automatically in the context of working, problem solving and living. It is learning as a side effect of other activities that is mostly not pre-organized, pre-planned or pre-structured. Its outcomes are experiential knowledge and skills.

Inquiring is all learning that leads to new (mostly explicit) knowledge and skills. It includes doing or being involved in research, as well as activities such as reading books and journals, going to conferences, executing practical or applied research, having discussions, comparing ways.

Creating refers to learning that is taking place in the context of the development of new tools, products, publications or services. These various ways of creating lead to design knowledge. It is when one tries to develop or design something that one discovers what one knows and especially, what one does not know. 


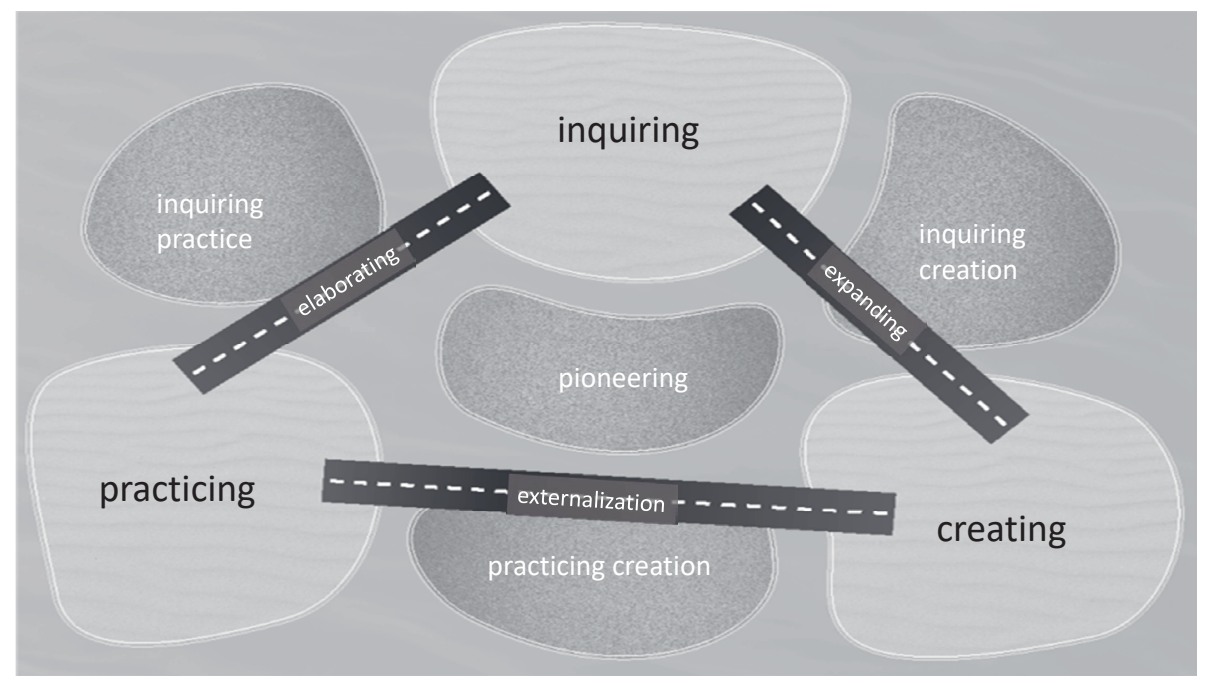

Figure 1. The learning landscape metaphor (Ruijters \& Simons, 2006).

\section{Bridges}

Practicing, inquiring and creating are the three basic components of the learning-landscape model. However, these basic forms of learning are not automatically interconnected. Just like islands in the sea, they tend to be separate. What one learns in practice is different from what one learns through inquiring or creating. Bridges were added to conceptualize the ways of learning that connect islands. Connecting islands is essential for several reasons: they bring more focus to someone's professional development (e.g., searching for new knowledge is the result of the questions raised by practice), it makes experiences explicit so as to be more possible to share, and by setting some distance to practice, it is possible to see patterns and to make double loops in learning, to name a few.

In bridges the outcomes of one way of learning (i.e., practicing, inquiring or creating) are connected to the other way of learning. The bridge between practicing and inquiring we call elaborating: making implicit knowledge originating from practicing explicit in order to be able to investigate it further and apply explicit knowledge in practice. The other way around the bridge of elaboration refers to the transfer of knowledge resulting from inquiry into practice. The bridge between inquiring and creating we call expanding. This bridge connects new knowledge with possible products, tools or services: what can be developed further based on this knowledge, what is interesting enough, and what are important target groups and markets? It also refers, the other way around, to finding gaps in knowledge that one needs to fill in order to be 
able to design, develop or publish. The third bridge is called externalizing and connects new products, services, tools and publications to practice. How can something new be implemented in practice? What new products or tools are needed in practice? Bridges can be crossed from two directions.

\section{Polders}

Thus far, we described three basic forms of learning (practicing, inquiring end creating): the three islands. These islands are not automatically connected. For professional growth, connections between the islands are necessary. All of these features of the work environment can be organized individually as well as in collaboration with others: with colleagues, coaches, managers and clients. Each of these categories of actors may bring different perspectives and contributions to implicit learning.

For the collective connections between islands, we use the term polder. This is new land between the islands. The processes of learning at two islands are integrated in a collective process. Professionals work together to integrate the learning processes at two or three islands.

The first polder between practice and inquiry is about investigating one's own practice. Practitioners study their own practice, primarily together. In the second polder (between inquiry and creation), creating and inquiring are combined and become inseparable. New products or services are designed in an alternating process of investigating and designing. It is this polder, which is necessary for innovation. The third polder is between practice and creation: practicing and creating are combined socially in improving the practice and infusing new ways of working. Semi-products make it possible for practitioners to work as and with designers to adapt products to their own context. The fourth polder component of our model is in the middle and makes use of all three islands. It is related to transformation of a practice by creating a space for piloting and experimenting by starting from scratch. Beforehand, one cannot determine what direction should be taken. In pioneering, practitioners carry out pilots and prototyping combining practice, research and creation. The polders and islands are positioned in the sea which stands for transformative learning, knowing that a whole new way of thinking is necessary.

The learning landscape metaphor has been used as a diagnostic tool to help organizations to find out how their separate learning interventions fit together (or not) and fit their purpose. It has also been used many times by now to design a repertoire of interventions or to redesign existing repertoires of interventions. It helps organizations to see where there is a need for cocreation or transfer of learning between different contexts through bridges. 


\section{Phase 3: learning preferences}

In order to understand and capture the diversity of learning from professionals, we wondered what the diversity was that characterized learning in general.

Based on the PhD thesis of Manon Ruijters (2006), we distinguished and tested five ways to learn i.e learning preferences. In our studies (Ruijters, 2006; Simons \& Ruijters, 2008), we work with overlapping patterns of preferences, that are developed over time and career and can be learned. Unfortunately, practitioners tend to use them as learning styles after all.

The five learning preferences were deduced from the literature as follows. In her article on two metaphors for learning, Sfard (1998) described a useful first distinction, the one between the acquisition and the participation preference. According to the acquisition preference, knowledge of the world is treated as the objective truth that can be transmitted from one person to another (Bruner, 1996).

The alternative assumptions of the participation preference (Sfard, 1998) state that: (a) there is no objective truth and knowledge is constructed in socialinteractions between people; (b) learning should be done by people themselves; at most they can be helped with this; we cannot do it for them; (c) learning is gradually becoming a member of a community of practice (or a culture, or a profession, or a field of science); this happens largely outside of institutions and tacit knowledge and skills play important roles in it.

Paavola, Lipponen, and Hakkarainen (2002) argued convincingly that the distinction between the acquisition preference and the participation preference should be supplemented with a third preference: discovery preference. They base this on an analysis of three theories of knowledge creation, from Engeström (1999), Bereiter (2002) and Nonaka and Takeuchi (1995).

The fourth preference (apperception, or observation and imitation) appears in the literature of management learning. Meggison (1996) called it "emergent" learning. It is a type of learning that is not planned; moreover, it is not recognized as being learning. It is learning perhaps best described as "on the spur of the moment", working on a highly complex issue, looking around, searching for what works, analyzing and copying it.

Theoretically, this way of learning relates mostly to the social learning theory of Bandura (1986) focusing on observation, imitation and modeling as vehicles for learning.

Finally, the fifth learning preference is based on Ericsson's deliberate practice theory (Ericsson, Krampe, \& Tesch-Romer, 1993). This theory describes how musicians, athletes and workers practice deliberately on a regular basis in order to reach higher levels of expertise or competence. The fifth learning 
preference, which we call the exercising preference, thus focuses on learning abilities with an active role of the learner who is consciously learning in collaboration with others in order to be able to function in a learning organization. For learning one needs guidance by experts and collaboration with others in a safe environment.

A short description of the five learning preferences is presented below.

\section{Apperception (imitation and observation)}

Learners who prefer apperception prefer to spot an expert in a particular field and they learn by example and good observation from people who are successful in practice. These learners are very interested in stories concerning best practice and what works. These learners are not keen on situations involving role-play and exercises. They will soon come to regard these as "childish". They prefer to learn in the real world (instead of a learning world) where they are challenged to perform and achieve in a complex environment. Part of the challenge here is to avoid mistakes or to turn a disadvantage into an advantage.

\section{Participation}

People who prefer the participation preference learn socially. The social side of learning is being emphasized: we learn with and from each other. Knowledge is not an objective concept; everyone has their own interpretation of what it is, but by communicating with others it is possible to arrive at a joint meaning. People who prefer participation learn by interacting and communicating. Interaction is essential for them. They need the cut and trust of discussion to sharpen and clarify their ideas, being forced to explain their thoughts, which, in turn, encourages feedback in the form of reactions and ideas from others. Learning is easiest for these learners within a group where the members are interested in and trust each other. Support in the form of a team coach, someone who can guide the group process, can be useful, but the division of tasks within the group and rotating chairmanship is a good alternative.

\section{Acquisition}

Acquisition learners attach great importance to the transfer of knowledge and the learning of skills. They often learn well when goals are set and learning processes are defined. They like to be taught by "experts", teachers who know their subject matter. After all, knowledge is objective, and it is important to gain knowledge in an unsullied environment. For these learners, mistakes should be avoided: making mistakes is a sign of planning errors, sloppy preparation 
or inadequate knowledge. These learners know what they want to learn and target their learning to achieving a concrete result. Regular testing is part of this learning process; after all, knowledge can be measured. Examination results give a clear indication to what extent the results have been achieved.

\section{Exercising}

Time and time again, exercising seeks to bring learning closer to the workplace, choosing forms such as on-the-job training, work experience and role-play. The greatest concern is whether what is learned can be applied in practice. For this reason, wherever possible, training is carried out in realistic situations; situations that reflect everyday practice as closely as possible. The core of this approach is that it is a "learning situation". This means that the environment must feel safe enough to dare making mistakes in it. The environment should also be uncluttered enough not to detract learners from their primary goal.

\section{Discovery}

Learning as "discovery" is based on the premise that life and learning are synonymous. We do not just learn during a course; we are always learning. There is no such thing as "not learning". Learning means finding our way through and understanding situations. Being conscious of this, teaches us a great deal about daily life and those unexpected events that confront us all. An important prerequisite is a large degree of freedom. Learners who prefer discovery like to go their own way. This does not necessarily have to be the most efficient path, as long as it is the most interesting one. These learners search for inspiration and meaning and find these in their environment, friends and the people around them. At this stage we have collected, through a 65 -item digital and paper scan, over 40,000 of learning preferences (not published yet). The output of the scans is always a pattern of overlapping preferences. Most of the time, people prefer two or three of the ways of learning and have a low score in one of the five. Furthermore, the preferences are not treated as stable learning styles, but as temporary patterns of preferences. We used these in various ways in practice: as a way to get to know each other, as a way to tune training and teaching to the majority of the learning preferences of learners, as way to differentiate between groups of learners and as a basis for learning how to learn approaches. In working with the learning preferences in practice with, for instance, judges and entrepreneurs, we found out that there are two other learning preferences besides our original five: intuitive learning and imaginary learning. Intuitive learning involves learning in socially high complex situations that starts from a broad collection of information, knowledge and 
opinions followed by a non-reflected basic feeling (from the stomach) that a certain solution or decision is the best way to go. The learning is more than checking and testing, looking for evidence and contra-evidence whether this is really the case. Some of our clients do not see this as learning, but we do. Imaginary learning is a kind of vivid scenario planned beforehand. Before and during court-sessions, judges are putting the puzzle together in their head, preparing themselves by walking through intrinsically (imagining inside their eyes) what possibilities there are for different participants to bring in and how to react. Learning occurs in checking what scenarios occur and whether all scenarios were thought of. In both kinds of learning extended experience of highly complex situations forms the basis of learning. Intuitive and automated knowledge play important roles.

\section{Phase 4: The learning professional}

In our 2014 article (Simons \& Ruijters, 2014) we did an extensive literature review, looking for historical changes in the concept of professionals We also tried to look for the core characteristics of professionals to be found in international publications. As a starting point we took an article of Gardner and Shulman (2005). They defined six characteristics of professionals.

When reviewing the literature, we found broad support for most of the principles of Gardner and Shulman (2005), but also some differences and extensions. We also found some principles in the literature that were missing in their approach. Moreover, we discovered that in their principles, there was a mixture of work-related and learning-related principles. In the end, this led to a set of eight characteristics of the work of professionals and a proposal to characterize the learning of professionals in eight other parallel characteristics.

The eight characteristics of a professional we described were the following (Simons \& Ruijters, 2014):

a) Commitment: They have a commitment to serve in the interest of clients and society.

b) Integrity: They have the will and ability to handle "not-knowing" and the unexpected with integrity.

c) Body of knowledge: They have abstract knowledge (body of knowledge), are willing and able to translate that into practice and are in connection with new developments in science.

d) Theory of action: They have a specialized set of professional skills and "theories of action".

e) Field of expertise: They have their own "field of expertise" within the profession. 
f) Professional community: They belong to one or more professional communities, has an orientation to work collectively and trans disciplinary in order to cope with complexity.

g) Autonomy: They are self-directed and autonomous in deciding what to do, based on their professionalism (as a result, not as a demand).

h) Authority: They are, under certain circumstances, seen as having expertise power; the opinion of a professional is seen as more valid than other nonprofessional opinions.

These were the principles deduced from the literature in combination with the Gardner and Shulman article. We concluded that commitment and integrity were requirements, the next four were qualities and the final two we called benefits (see Figure 2).

\section{Society - Client}

Benefits Autonomy \& Authority

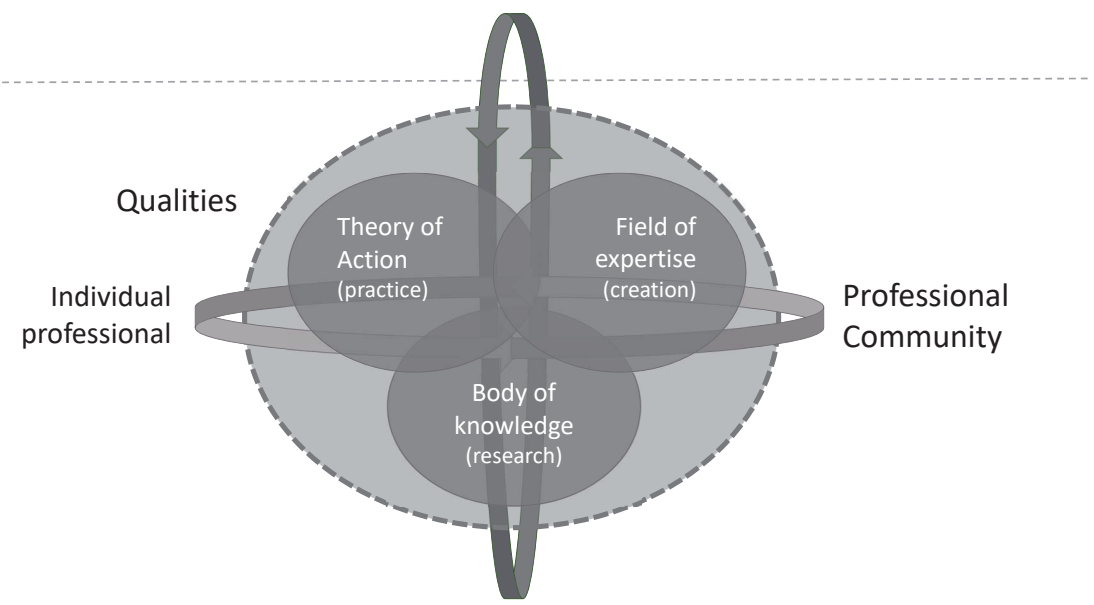

Requirements Commitment \& Integrity

Figure 2. Eight characteristics of a professional.

We concluded that being a professional is a choice not a state that is given by education or job-description alone. Choosing to remain a professional also requires that one is continuously updating the eight characteristics. Then we looked from these eight characteristics to the learning of professionals or in other words the characteristics of a learning professional (Simons \& Ruijters, 2014). These came partly from Gardner and Shulman (2005), partly from the literature and some were deduced by reasoning from the eight characteristics of professionalism as described above. 
Learning professionals:

a) have a commitment to take their own learning and development seriously.

b) are oriented towards reflecting on experiences of not-knowing and the unexpected.

c) are learning from theory and research.

d) have the willingness and ability to be reflective practitioners, of growing new knowledge from the contexts of practice.

e) continue to specialize and work in their field of expertise.

f) belong to one or more professional communities, have an orientation to work collectively and trans disciplinary in order to cope with complexity.

g) choose to be self-directed and autonomous in work and in learning. Professionals actively choose to be professionals and thereby, to be self-directed and autonomous.

h) have an orientation towards shaping the profession and to educating fellow professionals and newcomers. In these two ways they develop their authority.

\section{Phase 5: Professional identity}

In recent years we felt the need to add another item to our thinking on professionals and learning. It started with the thought that only a limited amount of all the learning that takes place in organizations concerns the addition or expansion of knowledge. It is increasingly and more frequently involving changes in the way of working or transformations. Professional identity is increasingly at play. Most people nevertheless continue to regard learning and development as the addition of knowledge and the development of skills. We rarely include the transformation of previously constructed thoughts (Illeris, 2014; Kegan, 2009). We devote only a limited amount of attention to the connection between the content and the person. For example, we neglect questions such as: "What does knowledge actually mean to you?", "Where does this fit with who you are and how you work as a professional?"

Thereby, professional identity is not a static phenomenon. It is a component of ourselves and - like ourselves - it is continually in development. Professional identity thus requires maintenance and attention. We see that, although professional identity should be addressed at a variety of points throughout the course of professional development, we devote relatively little or no attention to it.

Professional identity emerges in the interaction between individuals and their contexts. Professional identity thus involves our relationships with ourselves and our relationships to others. It connects self, others and the profession and is what uniquely characterizes a particular professional. According to Ruijters (2015a), a strong professional identity provides professionals with: 
- self-management: being able to choose your own course, considering your organization, profession and personal perspective;

- resilience: being able to deal with changes and developments without losing yourself;

- wisdom: the peace of mind to form a clear distinction between one's own identity and to deliver added value to others;

- excellence: drive and eagerness to learn to get the most out of yourself and (the exercise of) your profession (Ruijters, 2015c).

Ruijters' (2015a) model of professional identity (see Figure 3) has three major parts: half of the model represents the social self, the "we", half of the model represents the personal self, the "I". An overlay on these two sides represents the professional self. By consequence four elements appear: starting from the bottom, going to the top, these are: the personal self, the professional self, a professional frame and an institutional frame.

The personal self consists of the material self (everything for which we can put "mine" and for which we feel responsible), the spiritual self (that which sets us in motion) and the personal representation of the social self (how we relate within and to groups) (James, 1890). The professional self consists of one's own theory of practice (your own statement about how practical situations work, your professional norms and values), your personal knowledge base (what your favorite theoretical models are, what you know about the context, about yourself and how you develop) and your area of expertise (what you are good at and contribute to your colleagues).

Then there is a professional frame. It comes into existence in working with colleagues and with whom you attune your professional actions in the moment. It is about what you consider "good work" as a group (Shaffer, 2006).

And finally, the institutional frame is about the organization where you work, the religious community you are part of, or the union you are a member of. In essence, we see the concept of frame as an interpretative scheme that offers people a perspective "from which an amorphous, ill-defined, problematic situation can be made sense of and acted upon" (Schön, 1983). In our view, it reflects that each institution, or every professional group, has its own way of thinking and in doing that includes and excludes perspectives or members, which determine thinking and doing.

As mentioned, professional identity is not a constant and unchanging fact, but it is about coherence. The past, present and future, therefore, also have a connection with professional identity. This timeline is shown in the center of the model in Figure 3. A fingerprint is central to the model, symbolizing professional identity itself. 
Professional identity is what connects inalienably: who you are (person), the work you do (profession) and the context in which you shape it. Professional identity thus requires maintenance and attention. Figure 3 presents the complete model, showing the three fields (personal, social and professional) making four parts; the personal self, the professional self, a professional frame and an institutional frame with professional identity in the middle. The arrow represents the timeline, illustrating that there is continuous development.

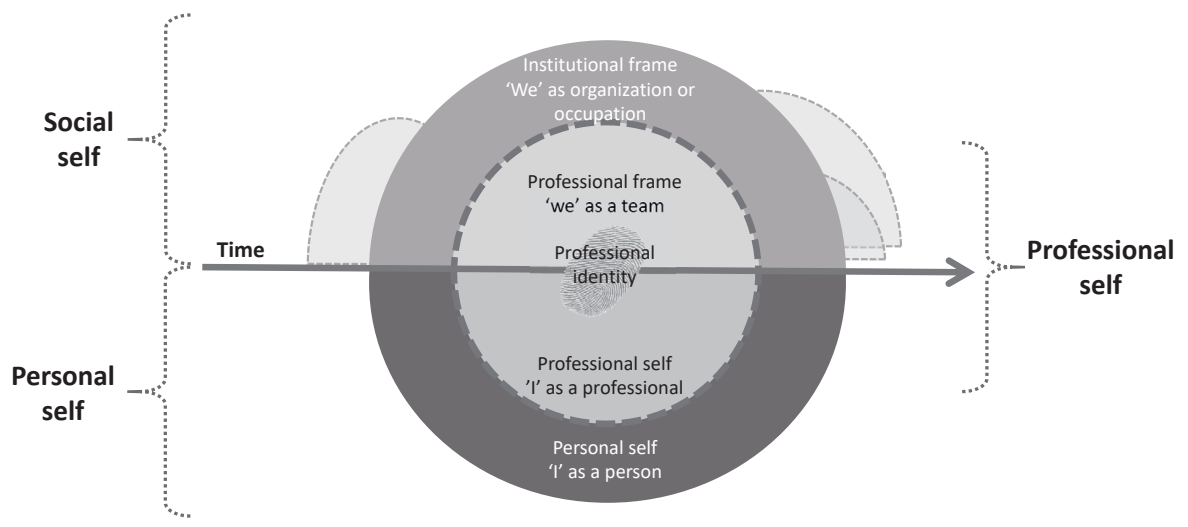

Figure 3. The model of professional identity.

\section{Discussion: Putting it all together}

Here we try to put all of this together in five steps:

a) What are the differences between our original models of professional and work-related models and the later ones?

b) How do learning preferences fit into our learning landscape?

c) How are professional identity and professional learning related?

d) What can be an integrative, combined model?

e) What does this mean for a professional learning culture?

a. What are the differences between our original models of work-related learning and professional learning and the later ones?

In our first articles (Simons \& Ruijters, 2001; 2004) we described a professional as a worker with a strong vision, a unique method of working and an aligned set of tools and techniques. Also, we stressed the importance of belonging to a professional organization. Moreover, the professional should be learning in three ways: elaboration, expansion and externalization. Thinking about the professional in this article was a tool to get a better grip on work-related 
learning. We believed that too much was looked at from the point of view of learning and too little from the point of view of the person who was learning.

In our 2014 article (Simons \& Ruijters, 2014), we further explored this thinking about the professional with a literature study. We took the step from the learning of professionals to professional learning, and we started to view professionalism as a choice. Eight characteristics of a professional were described. The original three reappear in the list of eight under new names: vision became an element of "field of expertise", methodology and tools and techniques became theory of action. The relation with a professional body now became being a member of various professional and organizational frames. Based on the literature review, new characteristics of professionalism were added: commitment, integrity, field of expertise, autonomy and authority. The learning professional model thus included the original concepts and brought important extensions.

The ways of learning of professionals distinguished then (elaboration, expansion and externalization) reappeared in the learning landscape model but divided into islands, bridges and polders (see below).

\section{b. What is the relationship between the learning preference and the landscape?}

The learning landscape model (Ruijters, 2006; Ruijters \& Simons (2006) was a model of learning professionals fitting the current use of the word (professionals in the broad sense of the word, thus not reserved for selected groups or specific professions), and originated from our thinking about learning from the professional. By now, with two models being frequently used next to each other, a frequently asked question became: how do learning preferences fit into the learning landscape?

Some of our students tried to integrate the learning preferences in the learning landscape. An attractive simple idea proposed by some, was that knowledge acquisition is on the island of inquiry, discovery on the island of creation and participation, exercising and apperception are three ways of learning on the island of practicing. When given more thoughts, it became clear that some ways of learning are more bridges and polders. Exercising is a bridge between the island of inquiry and the island of practicing, as well as a bridge from the island of creation to the island of practicing. Participation belongs more to the collective integrative kinds of learning in the polders. The more we were thinking about this, however, we found out that all ways of learning can take place on all three of the islands. Think, for instance, of apperception and creation: copying the art of creation from a field expert. Another example could be: participation on the island of inquiry: visiting a conference with a group of colleagues 
or doing a research study together. Moreover, we also found other connections between bridges and ways of learning, for instance discovering a new way to apply new knowledge on the island of practice or acquiring knowledge about a new way to apply new knowledge in a tool to be developed. Then, the same also holds for the polders and the five/seven ways of learning described above. Although here participation will be the dominant way of learning, the other four can be included.

We may conclude that the five/seven ways of learning are independent of the islands, bridges and polders. Some connections between the learning landscape parts and the learning preferences are more prominent than others, but there seem not to be exclusive relations.

\section{c. How are professional identity and professional learning related?}

Professional identity provides the basis for a professional to bring in the long-term perspective (past, present and future), the relation with personal identities and the contextual and organizational context. This provides a holistic integration of personal development and professional development, embedding this in the context of organizations and the profession. How did your personal and professional identity come forth from your material, social and spiritual self, the frames you feel connected to within an organization and a profession? A strong professional identity means an active choice to be a professional and to fulfil the eight criteria of a professional described above and the eight criteria for professional learning in the model of the learning professional. Professional identity has apart from this also a content dimension: what kind of profession do you feel related to (lawyer, doctor, teacher, nurse, etc.) and how strongly?

Where we had previously mainly focused on the distinction between implicit and explicit learning, thinking on and about professional identity also pointed us to the importance of the duo of individual and collective learning (Ruijters, 2015a).

\section{d. What can be an integrative combined model?}

Starting from our interest in learning and professionals, over the years, we have expanded and deepened our insights and perspectives in this area. We have increasingly taken the position that a professional must be a learning professional in order to remain of added value in our current society. In our last attempt we added identity, because we noticed that identity was playing an increasingly important role in our working existence.

Now we come to the point where we are looking for the connection between professionalism, learning and identity. This is because we are increasingly 
convinced that it is not simply about the technique of learning, but to make learning a part of your identity. So, we are looking for the learner identity: what inalienably characterizes your learning (the kind of learner you are and want to be). In doing so, we look for the lessons in our previous models and articles, what do they teach us about the learner identity of a professional, what questions does he or she has to ask to shape this.

Questions from the field of identity are:

a) Timeline: What did your learning look like in different phases of your life? What did learning look like in the different phases of your professional life? What does your learning look like now and how do you want to shape it in the future?

b) We - context - collective self: Which contexts (institutes, organizations, teams) do you relate to?

c) I - personal/professional-self: How do you know yourself? What is your material self? What is your spiritual self? What is your social self? What characterizes your body of knowledge? What characterizes your field of expertise? What characterizes your theories of practice?

d) Professional identity: What characterizes the connections between your profession and yourself and your organization?

Questions from the field of professionalism are:

e) Professional: Which discipline are you committed to? What does integrity mean to you? What is the body of knowledge in your profession? What is the theory of practice in your profession? What is your field of expertise within your profession? What do the professional frames look like where you work inside? Which autonomy is part of your profession? Which authority do you have in your profession?

f) Learning professional: How do you maintain your professionalism? How do you reflect on dilemmas? How do you connect research and practice? How do you ensure reflective practice? How do you develop your expertise? Which professional communities do you belong to? How do you develop as a professional? How do you contribute to the development of your colleagues?

Questions from the field of learning are:

g) Learning landscape: What is your personal landscape of learning?

h) Learning preferences: What characterizes your way of learning? 
These questions are of course not strictly separated. All questions are deepened by making connections with other fields. For example, you can deepen your learning in a team through the timeline, as well as through the learning preferences.

Ultimately, the key question is: what is the unique quality in your learning within your context and your profession? We suspect that working specifically on this question, during initial training and later professional existence, gives you more solidity as a professional. Table 1 presents a chart of questions that combines all of the above.

\section{e. What does this mean for a professional learning culture?}

What can organizations and their leaders do to facilitate a learning culture that helps professionals to maintain professionalism, professional identity and to develop themselves as learning professionals? The answer to this question is simple: providing professional spaces in which professionals can keep on developing themselves along the eight characteristics of the model of the learning professional.

This means:

- Facilitating life-long learning

- Organizing reflective sessions about professional dilemma's and norms and values in practice and profession

- Providing opportunities for connections with research and theory

- Organizing sessions for reflection on actions

- Giving space for the development of personal fields of expertise

- Supporting connections with professional and organizational communities of learning and organizational learning

- Giving room for autonomy in working and learning

- Supporting contributions to the profession and teaching newcomers and fellow professionals 


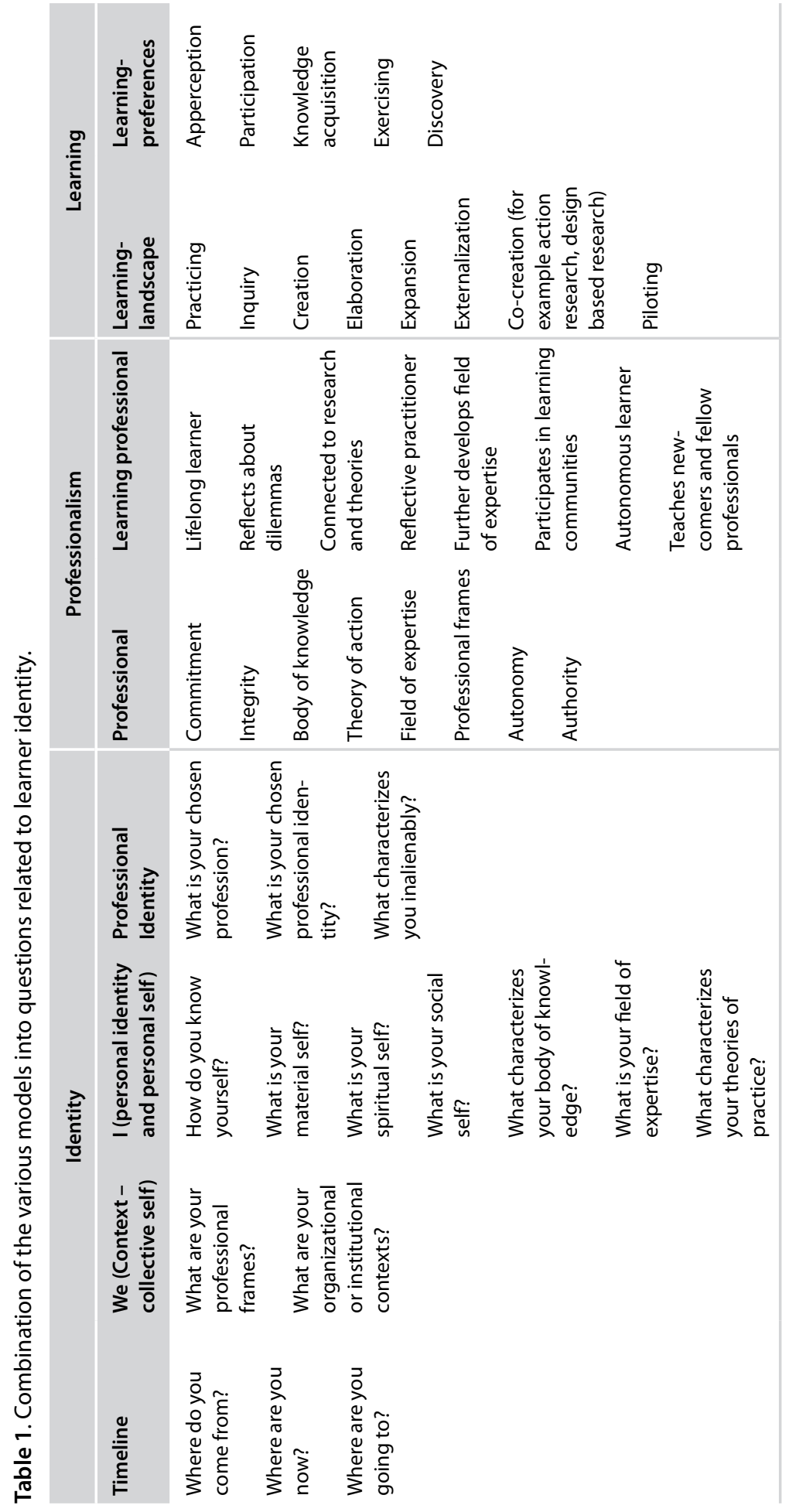




\section{Concluding remarks}

This article summarizes our previous publications and research about professionalism, professional learning, organizational learning and professional identity. The main aim, however, was to integrate these separate fields. This could be done through the introduction of the concept of learner identity: what inalienably characterizes your learning (the kind of learner you are and want to be) as a professional. Professional identity (with its timeline, relations with personal and social self) and choosing to be and stay a professional are at the basis of this concept. It integrates the organizational and professional collective frames of the self-chosen professional and it defines domains of learning of the learning professional as well as learning preferences. Together, the scheme of questions helps the professional to map his/ her learner identity in more detail. The characteristics of the learning professional can be translated into a set of eight characteristics of a professional learning culture: the spaces organizations need to provide for professionals when they want them to become and stay learning professionals.

Our current research focuses on the further development of this concept of learner identity and ways to facilitate professional learning cultures. Our future work will also focus on the relations between organizational learning and professional learning.

\section{References}

Bandura, A. (1986). Social foundations of thought and action: A social cognitive theory. Englewood Cliffs: Prentice-Hall.

Bereiter, C. (2002). Education and mind in the knowledge age. Hillsdale: Erlbaum.

Berings, M.G.M.C. (2006). On-the-job learning styles: conceptualization and instrument development for the nursing profession. PhD. Tilburg: Tilburg University.

Bolhuis, S. M. (1995). Leren en veranderen bij volwassenen. Een nieuwe benadering. [Learning and change with adults: a new approach]. Bussum: Coutinho.

Bruner, J. (1996). The culture of education. Cambridge: Harvard University Press.

Doornbos, A. J. (2006). Work related learning at the Dutch police force. PhD. Nijmegen: Radboud University.

Engeström, Y. (1999). Innovative learning in work teams: Analyzing cycles of knowledge creation in practice. In Y. Engeström, R. Miettinen, R.-L. Punamäki (Eds.), Perspectives on activity theory (pp. 377-404). Cambridge: Cambridge University Press. https://doi.org/10.1017/CBO9780511812774.025

Ericsson, K. A., Krampe, R. T., \& Tesch-Romer, C. (1993). The role of deliberate practice in the acquisition of expert performance. Psychological Review, 100(3), 363406. https://doi.org/10.1037/0033-295X.100.3.363 
Freidson, E. (2001). Professionalism: the third logic. Chicago: The University of Chicago Press.

Gardner, H., \& Shulman, L. S. (2005). The professions in America today: Crucial but fragile. Daedalus, 134, 13-18. https://doi.org/10.1162/0011526054622132

Greenwood, E. (1957). Attributes of a profession. Social work, July, 45-55.

Illeris, K. (2014). Transformative learning and identity. New York: Routledge.

James, W. (1890). The Principles of Psychology. Adelaide (Australia): eBooks@Adelaide. The University of Adelaide Library. University of Adelaide.

Kegan, R. (2009). What 'form' transforms? A constructive-developmental approach to transformative learning. K. Illeris (Ed.), Contemporary theories of learning (pp. 35-52). New York: Routledge.

Meggison, D. (1996). Planned and emergent learning. Management Learning, 27, 411-428. https://doi.org/10.1177/1350507696274002

Nolin, J. (2008). In search of a new theory of professions. Report of the University of Borås (Sweden) in the series Science for the professions, 4, 1-53.

Nonaka, I., \& Takeuchi, H. (1995). The knowledge-creating company: How Japanese companies create the dynamics of innovation. New York: Oxford University Press.

Paavola, S., Lipponen, L., \& Hakkarainen, K. (2002). Epistemological foundations for CSCL: A comparison of three models of innovative knowledge. G. Stahl (Ed.), Proceedings of CSCL 2002 (pp. 24-32). Hillsdale: Erlbaum. https://doi.org/10.3115/1658616.1658621

Ruijters, M. C. P. (2006). Liefde voor leren [Love for learning]. Doctoral dissertation, Utrecht University.

Ruijters, M. C. P., \& Simons, P. R. J. (2006). Het leerlandschap van organisaties [The learning landscape of organizations]. Develop, 2, 54-63.

Ruijters, M. C. P. (Ed.) (2015a). Je binnenste buiten. Over professionele identiteit in organisaties. [Your inside out. About professional identity in organizations]. Deventer: Vakmedianet.

Ruijters, M. C. P. (2015b). Praktijkverkenningen. [Exploring practice] M. C. P. Ruijters (Ed.), Je binnenste buiten. Over professionele identiteit in organisaties. [Your inside out. About professional identity in organizations] (pp. 145-190). Deventer: Vakmedianet.

Ruijters, M. C. P. (2015c). Professionele identiteit. [Professional identity]. In M. C. P. Ruijters (Ed.), Je binnenste buiten. Over professionele identiteit in organisaties. [Your inside out. About professional identity in organizations] (pp. 191-240). Deventer: Vakmedianet.

Ruijters, M. P. C., \& Simons, P. R. J. (2015). Professionaliteit [Professionality]. M. C. P. Ruijters (Ed.), Je binnenste buiten. Over professionele identiteit in organisaties. [Your inside out. About professional identity in organizations] (pp. 59-98). Deventer: Vakmedianet.

Schön, D. (1983). The reflective practitioner: How professionals think in action. New York, NY: Basic Books.

Senge, P. (1990). The fifth discipline: the art and practice of the learning organization. London: Random House.

Sfard, A. (1998). On two metaphors for learning and the dangers of choosing just one. Educational Researcher, 27, 4-13. https://doi.org/10.3102/0013189X027002004 
Shaffer, D. W. (2006). How Computer Games Help Children Learn. New York: Palgrave Macmillan.

Simons, P. R. J., \& Ruijters, M. C. P. (2001). Work related learning: Elaborate, expand, externalise. In L. Nieuwenhuis (Ed.), Dynamics and stability in VET and HRD (pp. 101-114). Enschede: Twente University Press.

Simons P. R. J., \& Ruijters M. C. P. (2004). Learning Professionals: Towards an Integrated Model. H.P.A. Boshuizen, R. Bromme, \& H. Gruber (Eds.) Professional Learning: Gaps and Transitions on the Way from Novice to Expert. Innovation and Change in Professional Education (pp. 207-229). Dordrecht: Springer. https://doi.org/10.1007/1-4020-2094-5_11

Simons, P. R. J., \& Ruijters, M. C. P. (2008). Varieties of work-related learning. International Journal of Educational Research, 47(4), 241-251. https://doi.org/10.1016/j.ijer.2008.07.001

Simons, P. R. J., \& Ruijters, M. C. P. (2014). The real professional is a learning professional. S. Billet, C. Harteis \& H. Gruber (Eds.), International Handbook of research in professional and practice based learning (pp. 955-985). Berlin: Springer. https://doi.org/10.1007/978-94-017-8902-8_35

Thijssen, J. (1987). Bedrijfsopleidingen als werkterrein. [Training and development as field of work]. Den Haag: Vuga.

Van Oeffelt, T., Ruijters, M. C. P., Van Hees, A., \& Simons, P. R. J. (2017). Professional identity, a neglected core concept of professional development. K. Black, R. Warhurst, \& S. Corlett (Eds.), Identity as a Foundation for Human Resource Development (pp. 237-252). London: Taylor \& Francis.

https://doi.org/10.4324/9781315671482-16

Van Oeffelt, T. P. A., Ruijters, M. C. P., \& Wempe, J. F. D. B. (2020). Towards collective professionalism: Lessons from a systematic review of literature on the history of professionalism. Manuscript in preparation. 